\title{
A Qualitative Investigation of an All-Female Group in a Software Engineering Course Project
}

\author{
Anthony Cox \\ Dalhousie University \\ Halifax, NS, Canada \\ amcox@cs.dal.ca
}

\author{
Maryanne Fisher \\ Saint Mary's University \\ Halifax, NS, Canada \\ mlfisher@smu.ca
}

\section{Executive Summary}

Past research suggests that single-sex educational environments provide many benefits to women's learning. Similarly, as indicated by their under-representation, it is known that there are problems in attracting and subsequently retaining women in information technology disciplines. In an effort to improve the enrollment and retention of women, we created a partial single-sex environment during a third-year university software engineering course. This course involved a multi-phase, one term group project, for which we assigned group membership based on sex, resulting in five men's groups and one women's group. Thus, in accordance with suggested practice, we employed an integrative approach where single-sex activities were integrated in a mixedsex classroom environment.

At the end of the term, the women voluntarily completed a survey about their experiences with their single-sex group, as compared to their experiences in mixed-sex groups in other courses. Here we qualitatively present the survey results, along with suggestions for educators who may wish to implement similar strategies with the intention of improving the educational experience for female undergraduates in disciplines where they are under-represented. In general, our findings show that women enjoyed the experience and that it allowed them to develop further confidence in their abilities, as compared to their experiences in mixed-sex groups. With respect to learning, the women felt that because they were more comfortable with group members they were more willing to attempt new tasks and reported instances of high levels of cooperation.

Consequently, we propose that better experiences may lead to improved retention of female students in these disciplines. To assist instructors who wish to employ a similar approach, we provide a discussion of our experiences and the lessons we learned. We believe that the successful application of single-sex activities in a mixed-sex classroom is founded on effective communication and monitoring. Instructors must be able to communicate their intentions to the students, rapidly identify and remedy any problems that occur, and be aware of actions that could lead to the development or strengthening of stereotypes. However, despite the challenge in using single-sex

Material published as part of this publication, either on-line or in print, is copyrighted by the Informing Science Institute. Permission to make digital or paper copy of part or all of these works for personal or classroom use is granted without fee provided that the copies are not made or distributed for profit or commercial advantage AND that copies 1) bear this notice in full and 2) give the full citation on the first page. It is permissible to abstract these works so long as credit is given. To copy in all other cases or to republish or to post on a server or to redistribute to lists requires specific permission and payment of a fee. Contact Publisher@InformingScience.org to request redistribution permission. activities, the benefits were encouragingly positive and worth the effort.

Keywords: single-sex groups, mixedsex groups, software engineering, informatics education. 


\section{Introduction}

It has been well established that, within North America, participation rates in Information Technology (IT) programs, such as Computer Science (CS) and Software Engineering (SE), are significantly male biased. Recent reports suggest that, at the university level, only $13.9 \%$ of students who declare CS as a major in Canadian universities are women (Canadian Association of University Teachers, 2007). This low figure is in spite of the disproportionately larger number of women enrolled in Canadian universities. Canada-wide average full time university student enrollment is composed of $56.7 \%$ women and $43.3 \%$ men, and part time university enrollment composed of $60.6 \%$ women and 39.4\% men (Canadian Association of University Teachers, 2007). At Dalhousie University, where our study was performed, the 2006 graduating class in the Bachelors of CS program was composed of $16 \%$ women and $84 \%$ men. If the graduating class is considered as representative of the CS program in general, Dalhousie, with a full-time undergraduate population of 10605 students, is just slightly above the national average for the proportion of women enrolled in CS.

The reasons for women's under-representation are complex and involve a wide variety of social and cultural factors, such as pervasive stereotyping against women who express technological interest (Cooper \& Weaver, 2003). While these factors must certainly be addressed, we posit that efforts will be misplaced if women are encouraged to enter a discipline where they cannot flourish. Thus, our focus is on the current educational environment and on potential interventions that will enable women who chose to engage in SE, CS, or other IT disciplines to successfully complete their program of study. This issue of retaining women who enroll in IT programs is extremely important. Cohoon (2006) documented, between 1994 and 2000, that women constituted $24 \%$ of CS undergraduates in the United States, but $32 \%$ of these switched to other majors. Whereas the vast majority of researchers (e.g., see Cooper \& Weaver, 2003, for a review) are attempting to investigate the reasons why women tend not to major in IT, there has been exceedingly little attention to issues that influence retention. The goal of this paper is to explore one possible mechanism that improves the educational experience for women enrolled in IT programs. It is hoped that by providing a more welcoming and enjoyable environment, women will be less likely to change programs and retention will be improved.

To address the possibility that women and men have distinct academic needs, educators have been turning to single-sex classrooms. In the United States, the federal Department of Education introduced regulations that provided public school districts and charter schools the flexibility to establish single-sex classes and schools (Salomone, 2006). However, a thriving debate exists as to whether single-sex environments are in fact a viable way to meet students' academic needs (see Salomone, 2006, for a review). In general, the evidence suggests that single-sex environments are particularly beneficial for women. Jimenez and Lockheed (1989) examined 3,265 Thai 8th graders' performance on standardized mathematics tests. The results revealed that single-sex schooling was effective for improving girls' scores, which the authors attribute to the impact of peers. In fact, there have been numerous, large-scale investigations on this topic, and they generally reveal improved performance for women and equivalent, or worsened, performance for men (e.g., Carpenter \& Hayden, 1987; Young \& Fraser, 1990; but see LePore \& Warren, 1997).

Single-sex environments may impact other aspects of students' lives in addition to their academic performance. Belcher, Frey, and Yankeelov (2006) randomly assigned sixth grade students to single-sex or mixed-sex classrooms. Students assigned to single-sex classrooms, regardless of sex, were reported to be more attentive, more interested in classroom activities, more likely to do additional independent work, had higher school-related self esteem, and found the classroom environment to be more orderly. Other researchers (e.g., Stowe, 1991) found that being in a singlesex, as compared to mixed-sex, physics class led high school girls to express more interest in pur- 
suing a physics-related career, increased class participation, and higher self-rated enjoyment of physics. Similarly, Jackson and Smith (2000) found that high school girls in single-sex mathematics classes reported higher feelings of confidence, increased enjoyment of the material, and viewed the environment as fostering their learning. These effects also impact feelings towards computing; girls who attend single-sex schools tend to report more positive thoughts about computing and greater feelings of competency than girls who attend mixed-sex schools (Jones \& Clarke, 1995). The authors attribute this difference to the fact that single-sex schools may result in girls having improved interaction with computers than in mixed-sex environments (Jones \& Clarke, 1995).

Our study is motivated by the evidence (e.g., Jones \& Clarke, 1995) that suggests single-sex educational environments might be particularly beneficial to women within the realm of IT. In IT programs, even when an individual's expertise (e.g., the years they have had access to a computer, the number of programming languages they know) is accounted for, women still typically report lower self confidence than men (Wilder, Mackie, \& Cooper, 1985). With respect to computing education, working in a mixed-sex environment often leads to women performing beneath their abilities, such that performance within single-sex groups is often much higher. This effect has been noted among various populations and contexts, including, for example, among college students in mathematics (Gwizdala \& Steinback, 1990) and among 11-12 year old children using a computer game (Light, Littleton, Bale, Joiner, \& Messer, 2000).

Although we wanted to proceed with investigating the impact of single-sex educational environments on women's undergraduate academic performance in IT, the low enrollment of women precludes such initiatives. It was not feasible, due to under-representation (i.e., about $16 \%$ of approximately 200 students), to form a single-sex environment for women in a CS program. That is, given a first year entry class of 60 students containing only 10 women, it is not economically possible to provide a separate set of classes for these 10 students. Furthermore, given potential concerns about using an exclusively single-sex approach (e.g., people have to work in mixed-sex environments in the "real-world," mixed-sex environments are important for socialization purposes), educators are encouraged to use an integrative approach, whereby some components of education are single-sex and other elements are mixed-sex (Cooper \& Weaver, 2003).

Thus, we opted to perform a partial (i.e., integrative) application in a mandatory third year introductory SE course. While enrollment levels required the use of an integrative approach, we were unable to find much guidance on the application of the technique as there has seemingly been little prior investigation. Thus, we explored the technique to evaluate its effectiveness and applicability. For the group-based course project, groups within the mixed-sex classroom were formed based on sex first, and then, by random assignment. Self-selection of groups is traditionally not permitted, even by other instructors in other terms, as the project attempts to simulate a "realworld" working environment where the make-up of software development teams is controlled by management, not by the choice of the team members. It is hoped that the arbitrary assignment to groups by the instructor will force students to develop socialization and cooperation skills with individuals with whom they may not have previously associated.

We next describe the classroom environment in which the study was performed, overview the course project, and then present the survey results through the female students' responses. We conclude with a discussion of our findings, emphasizing suggestions for educators who may opt to implement a similar concept in their university classrooms.

\section{The Classroom Environment}

The SE course at Dalhousie University is a "core" (required) third year course in the Bachelors of CS program. It is one term (i.e., four months, with three hours of instructional time per week) in 
duration, and every instructor who teaches the course, which varies from term-to-term, bases it on a major group project. Since this is a core course in the program, the majority of students has similar academic histories and enters the course with equivalent pre-requisite courses. The focus of the course is on the "software process," with the course examining software development from requirements elucidation, through implementation, to testing and deployment.

The course project had five components, the last four of which were graded: project definition, requirements specification, system design, implementation, and system testing. In the first phase, groups were told to create a "Vision Statement" for some arbitrary extension, enhancement, or improvement for a web-browser of their choice. In the next phase, a "round-robin" approach was used to permit each group to generate a "Software Requirements Specification" document for the vision statement of some other group. In this way, each group acted as a developer in writing their specification and as a customer for the group trying to specify their vision statement. In phase three, after more round-robin assignments, groups were asked to develop and document a detailed technical system design. Phase four had groups implement, before a two week deadline, the design of some other group. To ensure that implementation was possible, the instructor examined and modified the designs as needed. As well as actually generating source code, students were required to submit a "User Manual." In the last phase, after implementation was complete, each group then developed a comprehensive test plan for yet another group's implementation. Each of the four graded phases was worth one quarter of the project grade, or 10 percent of their final course grade.

As there were six groups and five phases, each group was able to work with a different code-base (i.e., browser) and customer for each phase. It was the instructor's desire that the groups become accustomed to a dynamic, rapidly changing work environment with constant differences in the code-base, task, and customer. The course was not intended to focus on programming and was instead meant to teach students to work in a cooperative manner using previously unseen source code and in a more realistic environment than provided by previous courses. To broaden student perspectives beyond the concept that software development is the production of source code, the course focussed on producing high quality written documents, not on programming and implementation.

For each phase, the groups had to submit a single document for the group. The groups were free to chose suitable notations, determine an appropriate document length, select the emphasis for each document, and develop suitable technical content. During each phase, students were encouraged to read the appropriate chapters of the course textbook, access online resources, and consult with the instructor (there was no assigned teaching assistant).

Within the curriculum for the Bachelor's of CS program, there are instructors that assign group projects in courses that precede the SE course. However, due to the annual variation in the assignment of instructors to courses, it is possible that some of the students may not have previously participated in a group project. As well, no other course in the CS program (except for advanced courses for which SE is a prerequisite) has a project that is a full term in duration or that is primarily focused on skills other than programming. It is possible that students participated in group work during an elective course necessary to satisfy the university's "breadth" requirement or during a course for a previously attempted (and possibly completed) program, but these latter options were not explored. 


\section{Methods}

\section{Participants}

In the course, offered during the Winter term of 2006 (i.e., January to April), there were 37 students. This led to six groups in total, with five male groups, composed of six members each, and one female group composed of seven members. One of the women in the group was a graduate student who was auditing the course to obtain relevant experience in a different discipline. While it was expected that her participation be minimal, she appeared to bond well with her all-female group and participated in a level that exceeded the instructor's expectations. In general, the graduate student's role was supportive in nature, as she was not from a CS background and was taking the course to obtain the skills necessary to work with computer programmers during the development of the computational models needed by her own research. Her provision of computing resources did not provide the all-women group with a specific advantage as the course instructor (first author) provided equivalent resources to the all-men groups.

It is not possible to report on the general academic ability of the students, as the authors are not permitted to access the students' academic records. However, the other evaluations used during the course (i.e., midterm and final exam) suggest that the 6 women are of different academic ability. While the group project significantly improved the grade that each woman received, the exam marks caused some of the women to not receive an " $\mathrm{A}$ " in the course. The highest exam marks (i.e., top three) in the class were obtained by male students, but these students' groups did not produce the highest quality projects. Consequently, there does not appear to be a strong relationship between overall academic ability and performance in group projects.

We originally intended to extend this research when the course was taught by the same instructor in 2007, but as there was only one woman in the course (19 students total), a replication was not possible. Instead, the single female student voluntarily engaged in a post-course interview (with the second author) and provided insight into her experience in a mixed-sex group. While a single student's thoughts do not form a satisfactory control group, they can potentially provide some insight into the differences between all-female and mixed-sex groups.

\section{Materials}

The survey (see Appendix for question details; original layout contained more response space) was composed of three main areas: background about the group's formation, group novelty, and the student's overall perceptions about her group. The survey was designed to expose group dynamics (e.g., leadership, allocation of work, methods for communication), as well as possible areas of conflict within the group, allowing us to examine conflict management skills. Many of the factors we investigated are likely indicative of group functioning regardless of sex, and hence, we did not survey the men's groups. Instead, our focus was to create a survey that was specifically oriented to elucidate the particular issues that the women faced by being in a single-sex group, as compared to their previous experiences in mixed-sex groups.

\section{Procedures}

Upon completion of the course, after the last project element had been submitted, but before the final exam, the members of the women's group were given a post-project survey. The students were informed that the survey was about their experience in their single-sex group, with a focus on providing insight into whether this approach should be adopted in the future. We distributed seven surveys, reminded the students that their participation was voluntary, and within a few weeks, all seven surveys were returned. The high compliance rate suggests that the students had strong feelings about the experience that they wished to communicate. 
To protect the students' anonymity, the completed surveys were returned in sealed envelopes to a researcher at a neighboring university (second author) with whom they had no previous contact. Before completing the survey, the students were informed that their instructor (first author) would not view the completed surveys while they were registered undergraduate students. To maximize anonymity, the surveys remained sealed for one calendar year, until after the students graduated.

When the surveys were reviewed, it became clear that there were well-defined group dynamics. As we wish to preserve the confidentiality of the students, there is some speculation in our understanding and we cannot make absolute claims. We believe that there was a self-appointed "group leader," a highly confident individual with good technical skills. As well, there was a clearly "weak" student who we believe was uncomfortable in programming, but likely had strong performance on the exams (perhaps unknown to the other students). There was also a group "mediator" who, in conversation with the authors after the course, admitted that she felt her programming skills were not as strong as those of other students and felt a need to compensate for this fact, partly through her mediation ability. It should be noted that programming skill affected less than $10 \%$ of a student's final course grade. Finally, the auditing graduate student was unidentifiable and said nothing to indicate her status on the questionnaire.

With respect to performance, it must be noted that the all-women group performed at a level that was clearly beyond that of the other (i.e., all-men) groups. They submitted an imaginative and novel vision statement (a transparent graphical layer to permit annotations to be added to web pages), and solid, technically superior documents for the other phases. All four graded phases were given a mark in the " $\mathrm{A}$ " range (i.e., above $80 \%$ ). They were also the only group to provide a demonstratively functioning implementation for phase 4 . In other terms that the same instructor has taught the course, no other group has yet to perform at such a high level. The single mixedsex group of the following year also produced high quality work, as most the most effective group that year, but did not achieve the same level of excellence as the all-women group. Thus, the inclusion of women into a group, whether an all-women or mixed-sex group, seems to have positive effects on that group's performance.

\section{Results}

For simplicity, the results will be presented according to four identified themes: the group's dynamics, perspectives on an all-women group, students' negative perceptions, and the impact and benefits of a single-sex group. Within each section, individual issues will be further discussed and accompanied by representative statements from the students. For contrast, we follow the experiences of the all-women group with a brief overview of the perceptions of the woman in the following year's mixed-sex group.

\section{Group Dynamics}

When it came to establishing leadership, six students claimed that the leader just selected herself for the position, and four elaborated that, initially, there was some distress about this action. For example, one student said, "She pretty much just assumed the position. When I asked if she was the leader, she said I can be, and no one contested. I didn't feel like causing friction." The response of one other student, presumably the leader based on her response, stated, "Leader is too strong a word. Everyone was equal in decisions. I just organized, delegated and set deadlines."

In terms of how tasks were assigned, all the students claimed it was a fairly egalitarian process, with individuals volunteering for the tasks that they preferred and the rest of the work divided amongst those remaining. "As a group we decided what needed to be done. People volunteered for what they were most comfortable with and if there was no preference, the work was distrib- 
uted equally." "If anyone was familiar with the content in any part, they got that part. Otherwise it was assigned. It was fair and the parts had equal amounts of work."

The students used a variety of methods to communicate about the project. This group was the only one to create an online forum (i.e., a WWW-based "wiki") to assist with frequent communication. All students reported the same types of interaction, at the same frequency, and agreed that it was sufficient; "We created an online forum and communicated daily via email. Most emails were sent to the whole group and archived. We also met as necessary or as much as possible face to face. This was enough."

With respect to how people worked towards getting their tasks completed, the members oscillated between working individually and then coming together and working in subgroups or as a whole. "For the most part, people worked independently on their task, but we frequently conferred with each other and received help when necessary, and occasionally, in a pinch, all members pitched in. This strategy worked very well. It required a lot of organization and maturity on the part of my teammates, but my trust in their work ethic paid off. It worked because my group was enthusiastic, hard working and organized." Another student supports this statement; "The work was separated individually, but we helped each other a lot. Not as a whole group, but subgroups."

This decision to work independently was not without pitfalls. "We met to divide up tasks, then worked on our own, with people working together at a distance by frequently exchanging half completed bits of code, for example. I'm not sure if this was a good plan or not. There were a number of cases where members worked for days on trivial problems because they didn't understand the problem. If we'd worked together more, that might have been avoided. On the other hand, the whole assignment would probably have been less work if only three or so of the more efficient members had worked alone."

The majority of disputes involved a feeling of not being heard by other group members. One individual elaborated quite extensively on this issue, saying, for example, “... I was really upset that I couldn't give my ideas and opinions within the group because I kept getting shut down, and had now been offended." Her response indicated that she had tried to persuade the group to move the project in a different direction than that specified by the leader, resulting in a dispute between her and the leader. "... I spoke with another group member who interceded, cleared-up that I wasn't attacking that person [the leader] personally and that she must stop taking everything so personally ... anyways, we just put it aside and worked well after." This third party confirmed this recollection, stating, "... if there was a dispute, I would act as a moderator, speak with both sides separately ... their concerns were valid and needed to be resolved or the group wouldn't have finished the project." The other group members were not necessarily informed of how the resolution was reached; "Two members were very opinionated on the design of the software system ... Although the details of the resolution are not known to me, another member tried to get them to become more amicable to each other, and it could have been their common, outspoken ways that exaggerated the issue." In general, members looked very favorably upon the mediator; "... she took it upon herself to mediate the dispute. She invested considerable effort, and the other two were able to maintain a solid working relationship for the rest of the term."

When asked whether all group members participated equally, six of the seven students said no; the one who agreed said, "All members participated equally almost all of the time." The other six responses indicated that one student did not participate equally, possibly because of ability. For example, "Overall, I feel that most people participated equally, except for one person... She had not learned the skills that were required in order to do her part (which was smaller than everyone else's). When someone else came up with a way to do her part (as a side effect of something else) she did very little after that." The students also tried to protect her from feeling excluded; "Everyone worked amazingly save one. She was given simpler jobs of lower priority so that if she 
didn't complete them satisfactorily it didn't affect the group. She of course didn't know her jobs were inconsequential." Two students were uneasy with this arrangement; one student stated, "It wasn't fair. There was one member that always needed guiding, and in the implementation stage, she did not really attempt to learn about the coding library we were using, nor attempt to understand the code. In a way, I think the group decided to avoid confrontation and gave her an easier section to do, which I am not sure was a good thing or fair."

Several students mentioned that they were surprised by the group's dynamics. For example, "I've never had group work so easy before. I was amazed at how much can be done when everyone pitches in a little part. It adds up to a lot. I also didn't expect the support; I spoke to the members as equals and received wonderful advice and support. We're continuing to work together on other projects, and even have become friends." Similarly, one student wrote, "... that we did get along as well as we did. That we succeeded in the end where most of the other groups failed. That we all liked each other in the end. No one lost lumps of hair or an eye!" This feeling of surprise at getting along was emphasized by another student; "How well we worked together and how comfortable I was with them by the end of the project." There was also surprise at how much work the group performed; one individual remarked, "The amount of work some team members put into our project was amazing. We always submitted high quality large documents as a result."

\section{Perspectives on a Single-sex Group}

We asked the women about the challenges that were unique to working within an all-female group as compared to a mixed-sex group. One student reported nothing was different, "I really cannot think of anything. If anything, this experience was the same as with a mixed-sex group, if not with less issues." Another student highlighted issues related to empowerment; "I found there was more pressure to do well in an all-female group because the males in mixed-sex groups usually don't think the girl can do as well and she gets small, unimportant work to do." The issue of outside obligations was also raised, "As a female group, I feel that we all felt that computer science was not our only focus in life. We all had family obligations, complex social lives, etc. This meant some of us were not as focused on class work as others." The remaining students listed sensitivity as being increased; "In a female group, I think sensitivity is an issue," and, "Dealing with members taking things personally ... guys don't do that."

Compared with their other group experiences, all group members stated high levels of enjoyment in working with an all-women group. There were various reasons for their enjoyment, one of which was simply that members could depend on each other to understand what life is like for women. For example, "I felt relaxed that I have a female group where we know each other's interests. In addition, we females take into consideration other people's feelings more than males." Likewise, "Yes, I enjoyed it. I found the other group members understood that as a woman I had a life outside my courses. We were also honest and understanding about our strengths and weaknesses in computer science." A third student agreed saying, "I enjoyed it tremendously. I find that males try to dominate a group and don't allow the girl(s) in a group to fully participate, unless she's extremely assertive."

Another reason they enjoyed the experience was perceived fairness; "I enjoyed it because everyone compromised ... everyone put a lot of time and effort into their parts. It was refreshing. At the same time, I didn't like it because it's very unrealistic, you will not find this situation in the real world of CS and we have to learn to deal with guys because they will be our bosses and coworkers." Similarly, "Yes, I thoroughly enjoyed it. I didn't have to prod or cajole anyone into doing anything. Everyone was so driven and excited about the project, the work flew by. This effect could easily happen in mixed-sex groups, but I've never seen it." 
Another student reflected upon the importance of cooperation and how it was motivating; "I enjoyed it because the work was distributed more equally, but I think that we did a lot more work than we should have, partly to make everyone feel that they were contributing, and partly to avoid conflict with those who came up with pointless tasks. But, I think we did a lot more useful work because no one wanted to let the group down." This sentiment was echoed by another student, "Yes, I did [enjoy it] but perhaps it was a combination of both the all-female group and the actual individuals ... our group worked well together in that we all wanted to do well on the project and everyone tried to be supportive of the others most of the time."

We then asked whether they believed the experience was useful for their learning. Again, the students agreed that overall it had positively impacted their learning, with emotional support and encouragement repeatedly listed as important influences. For example, "Since we tried to be supportive and encouraging of each other, it really made me want to try to keep learning, particularly about things to benefit the group. I don't think I would have had as much motivation to learn if the group had been different." This issue of support as a motivating factor is clear in one student's statement, "Initially I felt like I wouldn't be able to keep up with the group, because of the different academic backgrounds. Those feelings disappeared, but I'm not sure they would have [disappeared] in a mixed-sex group. It's hard to say for sure, but I think I felt more confident because we were all women." Another student highlights that she also felt more confident to try new tasks; "I probably would not have had the opportunity to do all the interesting things that I did unless I asked to do it, which I would not have in a mixed-sex group."

Three students directly raised the issue of comfort, presumably believing that higher levels of comfort led to a better learning environment. For example, "I felt more comfortable, I felt no need to defend my life outside school and thus more productive on the tasks at hand. The other members would share knowledge without making me feel like I should already know this information." Similarly, "I felt relaxed, organized, focused and emotionally satisfied." These claims were strongly supported by another student who said, "The amount of confirmation and communication was wonderful. We were all on the same page all of the time. We all knew what we had to do, when it was due, why the task was necessary, etc. I learned about the power of communication, trust in my team mates." Finally, one student's comments clearly demonstrated that the students engaged in active learning; "I think that this group was a rare example of girls working well together. Because we did, and because some had more knowledge in some areas than others, we were able to teach each other a lot. We all shared things we learned and passed on important findings." It is interesting that the student considers it "rare" for a group of women to work well together. Of the 5 all-male groups, two displayed obvious personality conflicts that were brought to the instructor's attention and three did not, suggesting that personal conflict is to be expected and is not an attribute of only all-women groups.

We then turned to the students' overall perceptions of their experience. Two students raised the lack of intimidation as a positive experience; "Males tend to be more technologically savvy, which intimidates females. I was not intimidated in this group," and, "I felt less intimidated by other members since they were female." This student raised a second issue of feeling like the group worked together towards a common goal; "I felt as it we were all on the same level with the same goals." Goal-oriented behavior was critical; as one student said, "My group consisted of a number of intelligent, driven, confident women. When working together the sheer power of work is amazing. I felt we could do anything. However, this is because we were able to come together to one vision."

Feeling understood was important to one individual; "The most positive aspect was the level of understanding we gave to other team members. We didn't expect everyone to be at the same skill level or have the same level of dedication to the course." The element of respect and sharing was also important, and one student stated, "Each of us respects the others and understands each 
other's feelings. I felt comfortable in every action I did. We were always in touch by email and never neglected any member's email."

Another facet that also received positive attention was communication. One student wrote; "The positive work ethic. The positive morale, the communal spirit, the clear communication. The sheer willingness to pitch in and get a good job done." This student, presumably the leader, also raised another issue of how the group worked together, without maintaining a clear hierarchy; "We didn't really have a hierarchy. We were a graph and I was a hub for everyone to touch in. We didn't need supremacy to respect." It should be noted that the "graph" being referred to means that the student felt she was the center-point of a communications flow in which group members communicated to each other through her. Equality in communication was echoed by another student who said, "It was nice to work in a group where almost everyone seemed to feel they had something to contribute. Most group members were able to step forward and take charge at some point. I'm not sure all girls would have been willing or able to do that in a mixed-sex group."

\section{Negative Perceptions}

While we were trying to create an effective learning environment for the female students, our efforts were not totally successful. The aspects of the experience that were considered negative were issues of elevated sensitivity, dealing with members with other, non-academic commitments, and with trying to cope with a group member who was not able to do the necessary tasks. For example, "Some team members had a large amount of focus outside the class. This showed up in the amount of work they were able to do for the group. One member was also at a very low level of technical skill. Some of us had to work extra hard to compensate, and as women, we didn't report this discrepancy to the prof." Likewise, "The emotional responses can be extreme ... differences in opinion can be taken personally. All-female groups seem to have no middle ground, either they mesh and pull off amazing things or someone's going to have to bury a body." This issue of emotional responses was emphasized in a long reply by one student who outlined the interpersonal conflict she experienced, and how this opposing group member embarrassed her in front of a friend who was not part of the course. She concluded, "I spoke with her right after the incident and she started crying and saying she's very stressed ... she said she's very sorry and she can apologize in front of everyone. I told her there's no need ..." Likewise, one student wrote, "There were a few personality clashes, but it was not too bad." One student listed no negative aspects, and one raised the issue of wanting a male's perspective on the project, "Computer science is dominated by males, and one reason for that may be that the discipline better suits the cognitive abilities of males than females. Perhaps it would have been good to have ideas from a male perspective." This last comment is discouraging, as it demonstrates to us that CS, as a discipline, might be directly or inadvertently suggesting to women that they are not as capable as men.

When we asked what experience was the most unexpected, we were further discouraged to see that at least one individual (not the same person as the last comment, above) was surprised that women can arrive at useful ideas in computer science; "We had the best project in the class and the idea came from a girl in our group."

There were mixed opinions about whether working in an all-women group should be encouraged in the future when a course involves group work. One student raised the issue that, "I don't like to think the sexes should be segregated. It opens the argument for giving the female group different assignments or other biased activities. Not everyone would be willing to accept that the groups are being segregated based on productivity - segregation opens many sexual stereotypes that would need to be addressed." Another student viewed the application of single-sex groups as useful for CS; "In areas where women have a tendency to back down and defer to what men think, 
I'd say all-female groups are worth looking into. Computer science is definitely one of these areas." Another individual suggested using groups to maximize diversity; "I think it should be encouraged for a few projects in order to give female students a different experience. Unfortunately, it won't happen often in the workplace, so it would not be a good idea to always do so."

Except for one student, all were silent about what an instructor could do to alter their experience to make it better. Although it did not directly answer our question, the one student who did respond stated, "I was angry at the instructor for doing this. I thought, 'what a sexist jerk.' I felt we absolutely had to succeed now or he would assume we failed because we were women. But I did come to like him [the instructor] at the end. We succeeded and I came to understand his teaching style." This last comment indicates the need for instructors to accurately and repeatedly explain their intentions. Although the instructor did explain in the classroom his reasons for forming single-sex groups, it is clear that he did not do so in a manner that was convincing and understood by all students.

\section{Impact and Benefits}

Although we do not claim that our intervention will have any long-lasting effects on the retention of women in CS, it is interesting that some of the women claimed that they felt differently about $\mathrm{CS}$ as a result of their experience. One woman wrote, "This experience made me feel less of a minority in CS." Another student wrote, "The 'last minute crunch, sleeping under your desk' is a lie. It doesn't need to be that way and my group proved it. With proper organization, communication, and drive last minute crunches aren't necessary. Also, I'm not a hardware/software guru. I have often felt thoroughly out of place in CS. This group taught me that you don't need to be a math genius, or some other A+ student. To be respected, diligent, patient and willing to work counts."

Two students wrote that they did not perceive any difference, although one of these two wrote, when asked if it this approach should be used in future courses, "Definitely. Especially in field related to computers and technology. I think males and females think very differently and when a female is outnumbered, she feels useless." This statement may indicate that it indirectly impacted her, at least in the short term, by making her feel useful.

One student's insights were encouraging with respect to potentially improving how she views women in CS; “There were points when I felt that my group wasn't really as strong as I expected, and I thought that maybe it was because women weren't as strong in CS as men. But then the other groups weren't as strong as I expected, either. So, the whole experience has taught me that students in CS need more practical experience, but that I would have learned that in a mixed-sex group anyways." Although it is possible that she would have arrived at this insight regardless of the group's composition, it is reassuring that she recognized that women are capable of performing well in CS.

We then asked if they had any advice to share with instructors who may be contemplating this idea in their courses. In general, the students were fairly encouraging, saying, "Go for it!" and, "It's an interesting idea. I'm not sure it would be as appropriate for subject areas that are less male dominated, but it's hard to say without trying." The students did carefully think about its applicability to CS as a discipline; "I think that since this class was a CS class, having an allfemale group was an excellent idea. I don't know if it would be beneficial or effective in other departments."

There was one opposing student; she said, "Don't do it ... for the sake of what's realistic we have to learn to handle, interact and socialize with members of the opposite sex. The interaction in university plays a big part of learning this." It is interesting to note that this student was the individual who was directly involved in the confrontation with the leader, and she had responded posi- 
tively about the learning experience and her enjoyment. It is comments like this one that support the use of an integrative approach with some single-sex and some mixed-sex activities within the educational environment.

Finally, we asked what advice, if any, they would share with women who may be presented with the idea of working in an all-women group. Six students responded, each raising a different issue. One said, "I would highly encourage this option over a mixed-sex group," whereas another person stated, "Give it a shot and provide feedback to the instructor. Try to differentiate if the problems you're having would also occur if you were in a mixed group." One slanted her opinion towards an explanation for why the study was undertaken; "It is important not to assume we are being lumped into an all-female group because we wouldn't work well with men. This is a tool to help us understand why we work the way we do and how we work differently from men." Another was more candid and stated; "Be aware of monthly cycles and corresponding sensitivity. I really didn't expect this to be an issue, but it was. Also, avoid the female tendency to talk about anyone in their absence. Be straightforward and blunt about any conflicts. It's difficult, but very important." A second student reinforced the issue of communication; "... Women are known for their massive amount of communication, this can be used to our advantage."

\section{A Female Perspective on a Mixed-Sex Group}

The single woman, in the following year's mixed-sex group, did not find her experience to be as enjoyable as that of the women in the all-female group. She believed that she was hindered from fully participating in the technological components of the project, as she felt obligated to perform more social tasks within the group. In her words, she was often busy with "peace making and problem solving" as a consequence of mediating and resolving the other member's conflicts. She also claimed that during meetings, she had to "provide distractions" when the male group members engaged in unnecessary competition or started to disagree and argue. In part, it appears that this student, whether consciously or not, felt obligated to fulfil the stereotypic view of women as "peace-makers."

The student also felt isolated and "under a microscope" in being the only female member of her group. She suggested that her actions were representative of her sex and that if she performed badly, she was "letting down her gender." While the all-female group also felt similarly, they did not feel as isolated as they could discuss the issue with each other and depend on each others' strengths. Fortunately, the academic ability of the lone female was quite good (i.e., her exam scores were among the top three students) and so her fears, while real, were unlikely to be realized.

The experience of being the solitary woman in her class caused the student to "question her role in CS." Without any other women with whom to discuss and share her experiences and concerns, she was forced to overly rely on introspection. We did not identify any similar comments from the all-female group.

\section{Discussion}

We now present some suggestions for university instructors who may wish to apply our initiative to their own learning environments. Our experiences identified areas where, if properly prepared, instructors can improve the quality of the student's educational experience. As well, we discuss the need for more diligent than usual monitoring of students so that sex-based group attributes are not used to develop or support stereotypes, particularly those that are harmful or undermine academic achievement. 


\section{Skills Training}

As one would expect with any group project, there were interpersonal conflicts that needed to be resolved. The women's responses clearly suggest that they were capable of using existing conflict management techniques in a successful manner. However, it also illustrates that students must have access to effective skills to address conflict when presented with group work. Instructors should ensure that such skills are available before forming groups, perhaps by teaching appropriate skills (e.g., empathic listening, use of mediators, negotiation).

Students must also be given the interpersonal skills to actually allow them to participate in group work. For example, students could be informed about how to equally share work and resources, how to communicate effectively, how to cope with feelings of uncivil and unfair treatment, or how to divert a co-workers aggressiveness or intimidation. Although these skills would presumably be highly useful for all students, they would potentially aid women's performance more substantially than men in disciplines where they are under-represented. As some women said, when working in mixed-sex groups, it is difficult for women to contribute in a meaningful way without feeling intimidated. Another proposed that men just "don't allow the girl(s) in a group to fully participate." It is important to note that we are not attempting to place blame on male students, but rather these opinions strongly reinforce the fact that there are beliefs about ability that are closely linked with one's sex, and these values will impact many aspects of students' university experiences. If one wishes to understand the reasons for women leaving CS, then these beliefs must be addressed.

Instructors must also remember that working with the opposite sex is a skill that may not be learned when same-sex groups are used exclusively. In an integrative environment, same-sex activities must be interspersed with mixed-sex activities, thus permitting students to learn the skills needed to communicate and work with opposite sex colleagues. Instructors must ensure that students are provided with a wide range of activities in which they can interact with faculty and students of both sexes. However, these activities may be provided by some other course within the program, and do not necessarily have to occur within the same course.

\section{Communication and Intervention}

Our experience indicates that educators who intend to proceed with a similar approach to the one used in this study must clearly explain to the students the reasons for the segregation, be prepared to communicate with the students openly about the initiative, and be fully supportive of the group. The students' comments, as presented in this paper, reveal that the students were quite introspective about the group dynamics. If our approach is implemented, it may be highly useful for students and instructors to meet at the end of the term, perhaps on a one-on-one basis, to reflect upon their experience. An opportunity such as this may allow students to form deeper insights, and inform the instructor as to the outcome. While communication is the key to effective education, it is even more important when dealing with sensitive issues related to one's sex. Instructors that wish to use sex-based group formation must be aware that their communication with the female group (i.e., the under-represented population) must be highly effective and prepared for involvement with the group. Furthermore, the group must clearly understand the instructor's intentions, and must be able to indicate when they need assistance in solving technical, pedagogical, or group-based problems.

On a related note, instructors need to have the ability to intervene if aspects of the course go awry, and do to so in a way that does not lay blame. For this reason, an instructor may not wish to inform the students of each upcoming task, as it leaves the opportunity to reassign groups under the guise of "yet another stage in the project," for example. Or, upon hearing the group is having interpersonal difficulties following a disagreement, an instructor could turn this dispute into a 
"teachable moment" by leading a class discussion on conflict resolution, and how teams in the workplace have to deal with similar issues.

While the all-female group in our study submitted technically superior work, this result may not always occur for a variety of reasons (e.g., a poorly selected project topic). It is important that instructors be aware that poor performance, by an all-women group, may be inadvertently and mistakenly associated with the sex of the group members. Should an all-women group, for any reason, not perform at an acceptable level, the instructor must promptly act to ensure that all students, both male and female, do not affiliate their performance with their sex. Possible interventions include a "random" restructuring of the groups, supplementary tutoring, and verbal support (e.g., "Oh, they were given an impossible task. The group that designed it was at fault. It's amazing how well they did in spite of the poor design they had to work with.") We stress here that one's sex must never be seen as a reason for their performance, whether it be a strong or weak performance.

The large body of research on under-representation in the workplace and academia shows that feelings of tokenism can be extremely detrimental to performance. As Saenz (1994) documented, being in the visible minority, such as being one of a small handful of women in a CS course, leads to a disproportionate amount of attention from peers and increases feelings of responsibility towards representing the group. Obviously, this increased pressure can spur some individuals to perform at a higher rate, but it could also lead to failure for others. In fact, when given a choice, the lone token woman in a group of men is more likely to want to change groups and expects to be stereotyped (Cohen \& Swim, 1995). Thus, while our study may have avoided this effect, it may have caused the women to form negative feelings, such as tokenism and feeling burdened with the need to achieve, which might not have happened in mixed-sex groups. However, at the same time, it might have reduced feelings of the tokenism at an individual level and shifted it to the group level. While these effects are difficult to assess, we note that the women in our study reported enjoying the experience and suggest that it be used again. As well, instructors must begin to alter academic climates from being perceived as threatening and intimidating, at least at an individual level (Aronson, 2002). The responses of the women seem to indicate that this study was a promising beginning in creating an improved learning environment.

One potential consequence of tokenism may be that students will worry that they will be unable to do a task, and the instructor will assume that their inability results from their sex. Thus, it might be possible that the students in our study attempted to hide incidents or not feel comfortable approaching the instructor for assistance as readily as the mens' groups. Again, this issue reflects the need to have a well-established line of open communication between the instructor and the student groups.

\section{Stereotypic Threat and Academic Achievement}

We believe it is necessary for instructors to understand how factors cause the activation of negative stereotypes and consequently affect intellectual performance, such as through the process of stereotypic threat (Inzlicht \& Ben-Zeev, 2000). Stereotypic threat refers to the extra cognitive load that is involved in worrying about one's performance such that it might confirm others' expectations of poor performance (e.g., Steele, 1997). Past research on women in mathematics and technical domains shows that negative stereotypes can undermine performance, and that the added stress of these stereotypes can harm one's academic evaluation (e.g., Spencer, Steele, \& Quinn, 1999). These stereotypes are highly pervasive; Inzlicht and Ben-Zeev (2003) found that simply allowing high-achieving women in mathematics to be in a room where they are outnumbered by men created a "threatening intellectual environment" and caused them to do poorly on a math test (p. 803). In our study, it is unlikely that stereotypic threat dissipated or was changed in any substantial manner; we did not attempt to reduce it in any way. However, based on the segre- 
gation of students for group work, it was fully acknowledged by the instructor, the women, and by the other students in the class. This segregation might have had a positive impact on the women, especially when they did perform well, as their high level of performance might also have spurred all members of the class to reconsider existing stereotypes and question their accuracy. Instructors who intend to carry out a similar study should understand some of the effects of stereotypes on performance and be capable of discussing these issues with the class.

In the case of the current study, the instructor was male, and the women might not have felt as comfortable discussing issues with him as they might with a female instructor. Thus, it might be better to have a mixed-sex instructional team; one could possibly have a female teaching assistant, for example, or "co-teach" the course. This arrangement would also lead to positive rolemodeling. Same sex role models have a significant impact on women, compared to men, as they more readily identify with role models and are more influenced by them, particularly in environments that are dominated by men (Lockwood, 2006). Using anecdotal reports of women in IT, Carlson (2006) reports that there is a desperate need for supporting, especially using social means such as mentoring or peer-support groups, women who enroll in the discipline. It can be seen that, albeit not intentionally, putting all the women in the same group provided a peer-support mechanism that may have helped the participants.

It is possible that, by random chance, the women assigned to a same-sex group might be of less than average academic ability. When such a situation occurs, it is crucial that the instructor carefully monitors the group and is prepared to intervene. It may be the case that the single-sex environment reduces anxiety and the potential effects of stereotypic threat, thus improving the women's performance. However, placing several female students with weak academic ability in the same group may lead to a poorly performing group that could unintentionally create or reinforce all students' stereotypical views. To avoid this possibility, instructors could assign a female co-instructor or teaching assistant to mentor and support the female group. Instructors could also avoid the open distribution of group marks to increase the anonymity of the groups. Finally, instructors could re-structure the groups to "simulate a dynamically changing workplace environment."

It may not be necessary to intervene when the students are simply meeting predetermined expectations. If a group's members know that they have below average skills and they thus expect to get a below average grade, it is unlikely that they will be surprised or upset when they receive a below average grade. It is also likely, unless this is a first year course, that the rest of the class knows of the group's ability and expects them to get a poor grade. Thus, intervention can prevent the expected from occurring, which as suggested by Bennett, Ordonez, \& Gilliland (2003) leads to a student perception of unfairness.

We also suggest that instructors use a flexible marking scheme when using same-sex groups. Thus, if intervention and assistance is needed to ensure that a group is not identified as inferior or incompetent, the instructor has a mechanism to ensure that marks are fairly assigned. Rigid schemes prevent an instructor from penalizing or rewarding students when intervention is performed.

\section{Limitations}

While this study is revealing with regard to the potential benefits and disadvantages of forming a same-sex group, our findings must be considered with respect to the limitations of the study. We readily admit that we would have desired a considerably larger sample size and would have preferred to base our discussion on more than a single group. However, the size of the CS program at Dalhousie and the number of women that are enrolled are limiting factors over which we can exert no control. These circumstances also prevented us from fully examining women's experiences 
in mixed-sex groups. It would be highly desirable to replicate this study at different institutions with larger programs and more female students. It would also be beneficial to use a modified survey that would be applicable to all-male groups, thus permitting the identification of issues that are common to all groups or unique to all-male and all-female groups. As we did not have a well defined control group, it is possible that some of our findings may have alternative explanations.

When we performed this study, we were predominantly focusing on improving women's experiences in a discipline in which they are under-represented. Unfortunately, our efforts could also have a negative effect on the men in the course as they were not given the opportunity to explore the skills needed to work effectively with female group members. It can also be suggested that the women were prevented from developing the skills needed to work with men. We believe that same-sex groups must be employed in an integrative environment and are not a tool to be used all the time, or for all group activities. The use of single-sex groups is an important and potentially effective tool that must be used in conjunction with mixed-sex group activities to ensure that students develop the necessary skills to work with colleagues of the opposite sex. However, we believe that group-work in other courses, and particularly in courses where women are more equally represented, is a better environment for these skills to be developed.

Group dynamics are highly influenced by a variety of factors (e.g., employment and family matters) and are constantly changing as these factors change. Our study was performed at the end of the course and only captures, using hindsight, an overall perspective of the experience. The interactions and changing relationships of the group members are not as accurately captured as they would have been using surveys administered during the term.

It is hoped that the experience of being in an all-women group was positive and beneficial to the participants. As no follow-up study was performed, we can never be certain of the long-term consequences of the study. While one of the participants has since found employment and indicated that the experience in the course was positive and provided excellent preparation for the workplace, such anecdotal evidence is not sufficient. In future work, longitudinal studies are needed to accurately assess the impact and consequences of using same-sex groups.

While this study examines the effects of group membership based on sex, it is possible that the practice is of value in other situations. Specifically, Schofield (1995) found that many of the factors that influence female use of a U.S. high-school computer center are equally applicable to cultural groups such as African Americans. As well, the technique may be of value for socio-cultural minorities who are not visibly evident. It falls on future research to identify when, and where, homogeneous groups can be used in a heterogeneous educational environment.

\section{Conclusion}

Our use of an all-female group was highly successful in the term when it was used. The group submitted the most complete and highest quality documents and software. However, we did not fully examine the students' actual academic ability and are unable to determine whether this result was the consequence of the all-female project group, or because they were coincidently more competent and capable than the other groups. As there did not appear to be a relationship between exam marks and group performance, we do not believe that the all-female group's performance is solely due to the academic ability of the most capable members.

We found that although the female group had the most successful project, potentially indicating a performance increase, there was seemingly heightened tension among group members that magnified interpersonal conflict. While conflict is presumably common in student groups regardless of the course or the people involved, we expect that all-women groups may maximally benefit being taught techniques for conflict management. 
As well, during a post-course survey, it was suggested that the women felt they were being essentially 'set up to fail.' While this was certainly not the case, the comment indicates that instructors must strive to ensure that their intentions are clear in sex-based issues. Even though the instructor (a male) was endeavoring to create a positive learning environment for the female students, their preconceptions had the potential to derail the instructor's good intentions. Instructors should certainly consider using sex-based group formation but must be aware that the potential for negative effects, such as reinforcing stereotypes, requires that they have strong channels of communication with the students so that they can identify, and resolve, any problems that occur.

In summary, we found that while placing all the women in a SE course into a single, unified group allowed them to perform at a level that exceeded that of the all-male groups in the class, the practice created new, unexpected issues that need to be addressed to improve and facilitate learning. However, although difficult to apply, sex-based group formation resulted in a positive experience for all of the women in our study, thus identifying a powerful tool for instructors to use when teaching under-represented populations. The results suggest than an integrative educational environment may help improve the retention of women in IT programs.

\section{References}

Aronson, J. (2002). Stereotype threat: Contending and coping with unnerving expectations. In J. Aronson (Ed.), Improving academic achievement: Impact of psychological factors on education (pp. 279-301). San Diego, CA: Academic Press.

Belcher, C., Frey, A., \& Yankeelov, P. (2006). The effects of single-sex classrooms on classroom environment, self-esteem, and standardized test scores. School of Social Work Journal, 31, 61-75.

Bennett, C., Ordonez, L., \& Gilliland, L. (2003). Grade expectations: The effects of expectations on fairness and satisfaction perceptions. Journal of Behavioral Decision Making, 16, 375-395.

Canadian Association of University Teachers. (2007). CAUT Almanac of Post-Secondary Education in Canada. Ottawa, ON: Author.

Carlson, S. (2006). Wanted: Female computer-science students. The Chronicle of Higher Education, 52, A35.

Carpenter, P., \& Hayden, M. (1987). Girls' academic achievements: Single-sex versus coeducational schools in Australia. Sociology of Education, 60, 156-167.

Cohen, L., \& Swim, J. (1995). The differential impact of gender ratios on women and men: Tokenism, selfconfidence, and expectations. Personality and Social Psychology Bulletin, 21, 876-884.

Cohoon, J. (2006). 'Just get over it or just get on with it:' Retaining women in undergraduate computing. In J. Cohoon \& W. Aspray (Eds.), Women and information technology: Research on underrepresentation, pp. 205-238. Cambridge, MA: MIT Press.

Cooper, J., \& Weaver, K. (2003). Gender and computers: Understanding the digital divide. Mahwah, NJ: Lawrence Erlbaum.

Gwizdala, J., \& Steinback, M. (1990). High school females' mathematics attitudes: An interim report. School Science and Mathematics, 90, 215-223.

Inzlicht, M., \& Ben-Zeev, T. (2000). A threatening intellectual environment: Why females are susceptible to experiencing problem-solving deficits in the presence of males. Psychological Science, 11, 365-371.

Jackson, C., \& Smith, I. (2000). Poles apart? A exploration of single-sex and mixed-sex educational environments in Australia and England. Educational Studies, 26, 409-422.

Jimenez, E., \& Lockheed, M. (1989). Enhancing girls' learning through single-sex education: Evidence and a policy conundrum. Educational Evaluation and Policy Analysis, 11, 117-142. 
Jones, T., \& Clarke, V. (1995). Diversity as a determinant of attitudes: A possible explanation of the apparent advantage of single-sex settings. Journal of Educational Computing Research, 12, 51-64.

LePore, P., \& Warren, J. (1997). A comparison of single-sex and coeducational Catholic secondary schooling: Evidence from the National Educational Longitudinal Study of 1998. American Education Research Journal, 34, 485-511.

Light, P., Littleton, K., Bale, S., Joiner, R., \& Messer, D. (2000). Gender and social comparison effects in computer-based problem solving. Learning and Instruction, 10, 483-496.

Lockwood, P. (2006). "Someone like me can be successful”: Do college students need same-gender role models? Psychology of Women Quarterly, 30, 36-46.

Salomone, R. (2006). Single-sex programs: Resolving the research conundrum. Teachers College Record, $108,778-802$.

Schofield, J. (1995). Computers and classroom culture. Cambridge, MA: Cambridge University Press.

Saenz, D. (1994). Token status and problem-solving deficits: Detrimental effects of distinctiveness and performance monitoring. Social Cognition, 12, 61-74.

Spencer, S., Steele, C., \& Quinn, D. (1999). Stereotype threat and women's math performance. Journal of Experimental Social Psychology, 35, 4-28.

Steele, C. (1997). A threat in the air: How stereotypes shape intellectual identity and performance. American Psychologist, 52, 613-629.

Stowe, L. (1991). Should physics classes be single-sex? Physics Teacher, 29, 380-381.

Wilder, G., Mackie, D., \& Cooper, J. (1985). Gender and computers: Two surveys of computer-related attitudes. Sex Roles, 13, 215-228.

Young, D., \& Fraser, B. (1990). Science achievement of girls in single-sex and co-educational schools. Research in Science and Technological Education, 8, 5-20.

\section{Appendix: Post-project Survey}

\section{BACKGROUND}

Please describe the structure of your group.

1) How many women were involved in your group?

2) Was there a leader? If so, how was this determined?

3) How was work assigned? Was this fair? Why or why not?

4) How frequently did the group interact by email and face-to-face? Was this enough?

5) How did the group work? For example, did people work individually and then meet as a group, or did everyone work together? Was this a good strategy? Why or why not?

6) How were disagreements resolved? Without mentioning names, please describe something that happened that needed resolution.

7) Did all members of the group participate equally? If someone did not meet their obligations, how was this handled? 


\section{GROUP NOVELTY}

Please think about past experiences you have had in mixed-sex groups while in university courses.

1) What were some of the challenges you faced working within an all-female group that you have not experienced in mixed-sex groups?

2) Did you enjoy working in an all-female group, compared to your other group experiences? Why or why not?

3) Do you think working in an all-female group was useful for your learning? Why or why not?

\section{OVERALL PERCEPTIONS}

Please think for a moment about your general feelings about your recent experience in the allfemale group.

1) What did you find to be the most positive aspect(s) of working in an all-female group?

2) What did you find to be the most negative aspect(s) of working in an all-female group?

3) Thinking about your group, what experience was the most unexpected?

4) Has working in an all-female group changed your perception of Computer Science? How?

5) Do you think that working in an all-female group should be encouraged in future courses that involve group work? Why or why not?

6) Was there anything the instructor could have done to make the situation easier? For example, would an assigned group leader have been beneficial?

7) Is there any advice that you would like to share with instructors who may be thinking of adopting the idea of all-female groups in their courses?

8) Is there any advice that you would like to share with female students who may be presented with the idea of being placed in an all-female group in their course?

9) Do you have any additional comments about anything that is not covered by one of the previous questions?

\section{Thank-you for participating!}

\section{Biography}

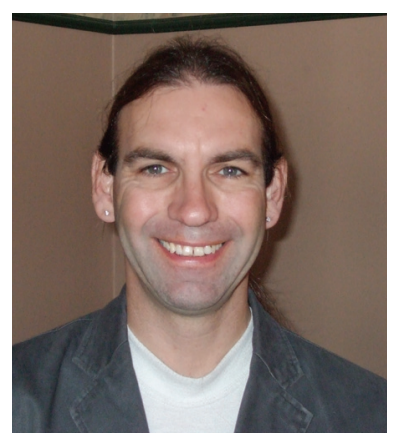

Anthony Cox completed his doctorate in Computer Science at the University of Waterloo on the use of markup and textual databases in support of software maintenance. His research now focuses on the human factors of computing, empirical studies of programmers, applied psychology, and sex differences in computer use. He is a co-director of the Centre for the Psychology of Computing and has served as a member and chair of the Dalhousie Senate Committee on Learning and Teaching. 


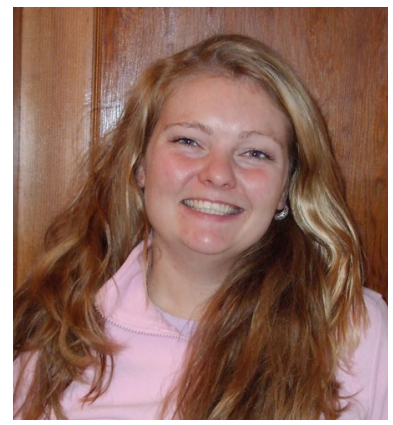

Maryanne Fisher completed her doctorate in Psychology at York University on female intra-sexual competition. She is currently an assistant professor at Saint Mary's University in the Department of Psychology. Her current research examines gender and sex differences in a wide range of areas from an evolutionary perspective. She is a codirector of the Centre for the Psychology of Computing, as well as an adjunct professor in computer science and a faculty member in the Women Studies Program. 